\title{
Streptomyces leeuwenhoekii sp. nov., the producer of chaxalactins and chaxamycins, forms a distinct branch in Streptomyces gene trees
}

\author{
Kanungnid Busarakam • Alan T. Bull • \\ Geneviève Girard · David P. Labeda • \\ Gilles P. van Wezel • Michael Goodfellow
}

Received: 8 November 2013 / Accepted: 11 February 2014/Published online: 7 March 2014

(C) Springer International Publishing Switzerland 2014

\begin{abstract}
A polyphasic study was carried out to establish the taxonomic status of an Atacama Desert isolate, Streptomyces strain $\mathrm{C} 34^{\mathrm{T}}$, which synthesises novel antibiotics, the chaxalactins and chaxamycins. The organism was shown to have chemotaxonomic, cultural and morphological properties consistent with its classification in the genus Streptomyces. Analysis of 16S rRNA gene sequences showed that strain C34 ${ }^{\mathrm{T}}$ formed a distinct phyletic line in the Streptomyces gene tree that was very loosely associated with the type strains of several Streptomyces species. Multilocus sequence analysis based on five house-keeping
\end{abstract}

Electronic supplementary material The online version of this article (doi:10.1007/s10482-014-0139-y) contains supplementary material, which is available to authorized users.

K. Busarakam · M. Goodfellow ( $\square)$

School of Biology, University of Newcastle,

Newcastle upon Tyne NE1 7RU, UK

e-mail:m.goodfellow@ncl.ac.uk

A. T. Bull

School of Biosciences, University of Kent,

Canterbury CT2 7NJ, UK

G. Girard · G. P. van Wezel

Molecular Biotechnology, Institute of Biology, Leiden

University, P.O. Box 9505, 2300RA Leiden,

The Netherlands

D. P. Labeda

National Center for Agricultural Utilization Research, USDA-ARS, Peoria, IL 61604, USA gene alleles underpinned the separation of strain $\mathrm{C} 34^{\mathrm{T}}$ from all of its nearest phylogenetic neighbours, apart from Streptomyces chiangmaiensis TA- $1^{\mathrm{T}}$ and Streptomyces hyderabadensis $\mathrm{OU}-40^{\mathrm{T}}$ which are not currently in the MLSA database. Strain $\mathrm{C} 34^{\mathrm{T}}$ was distinguished readily from the $S$. chiangmaiensis and $S$. hyderabadensis strains by using a combination of cultural and phenotypic data. Consequently, strain $\mathrm{C} 34^{\mathrm{T}}$ is considered to represent a new species of the genus Streptomyces for which the name Streptomyces leeuwenhoekii sp. nov. is proposed. The type strain is $\mathrm{C} 34^{\mathrm{T}}\left(=\mathrm{DSM} 42122^{\mathrm{T}}=\right.$ NRRL B-24963 $\left.{ }^{\mathrm{T}}\right)$. Analysis of the whole-genome sequence of $S$. leeuwenhoekii, with 6,780 predicted open reading frames and a total genome size of around $7.86 \mathrm{Mb}$, revealed a high potential for natural product biosynthesis.

Keywords Streptomyces $\cdot$ Polyphasic taxonomy · Atacama Desert · Natural products . Genome sequence

\section{Introduction}

Novel actinomycetes, notably streptomycetes, from extreme habitats are proving to be a potentially rich source of new bioactive natural products that can be developed as resources for healthcare. Streptomycetes account for about $40 \%$ of all known natural products and their genomes typically contain over twenty biosynthetic gene clusters that encode for known or 
predicted secondary metabolites (Goodfellow and Fiedler 2010; Bérdy 2012). Although an underexplored resource, it is difficult to discover new chemical entities from known streptomycetes as screening them tends to lead to the costly rediscovery of known compounds (Busti et al. 2006; Williams 2008). Consequently, innovative strategies are needed to selectively isolate, dereplicate and identify new Streptomyces species for pharmaceutical screening programmes, as exemplified by the taxonomic approach to drug discovery recommended by Goodfellow and Fiedler (2010). This strategy proved to be effective in the isolation of novel streptomycetes from deep-sea sediments, as illustrated by the discovery of caboxamycin, a new benzoxazole antibiotic produced by a Streptomyces strain that was isolated from sediment collected from the Canary Basin in the Atlantic Ocean (Hohmann et al. 2009). We have recently applied a similar strategy to study actinomycete communities in another neglected biome, the Atacama Desert in Northern Chile (Bull and Asenjo 2013).

The Atacama Desert is the oldest and driest desert on Earth having evolved over several million years of aridity and hyper-aridity (Gómez-Silva et al. 2008). Environmental conditions in the desert have been considered too extreme to support any form of life given the dearth of liquid water, paucity of organic matter, presence of inorganic oxidants and high levels of UV radiation. Despite these harsh conditions, phylogenetically novel actinomycetes, especially streptomycetes, have been isolated from soils collected from hyper- and extreme hyper-arid regions of the desert (Okoro et al. 2009; Bull and Asenjo 2013). The names of three of the putatively novel streptomycetes have been validly published as Streptomyces atacamensis, Streptomyces bullii and Streptomyces deserti (Santhanam et al. 2012a, b, 2013) and two additional Streptomyces strains have been shown to synthesise new antibiotics and anti-cancer compounds, the atacamycins, chaxalactins and chaxamycins (Nachtigall et al. 2011; Rateb et al. 2011a, b; Bull and Asenjo 2013). Another putatively novel Streptomyces strain from high altitude Atacama Desert soil produces novel aminobenzoquinones, the abenquines, which show inhibitory activity against bacteria and dermatophilic fungi (Schulze et al. 2011).

The present study was designed to establish the taxonomic status of Streptomyces strain $\mathrm{C} 34^{\mathrm{T}}$ isolated from hyper-arid Atacama Desert soil, which produces the chaxalactins and chaxamycins. A polyphasic taxonomic study showed that this isolate belongs to a new species, for which we propose the name Streptomyces leeuwenhoekii sp. nov.

\section{Materials and methods}

Selective isolation, maintenance and cultural conditions

Strain $\mathrm{C} 34^{\mathrm{T}}$ was recovered from a hyper-arid soil sample collected from the Chaxa de Laguna, Salar de Atacama of the Atacama Desert $\left(23^{\circ} 170^{\prime} \mathrm{S}, 68^{\circ} 100^{\prime} \mathrm{W}\right)$, near Tocanao (Okoro et al. 2009). The organism was isolated on starch-casein agar supplemented with actidione and nystatin (each at $25 \mathrm{~g} \mathrm{ml}^{-1}$ ) after incubation at $28{ }^{\circ} \mathrm{C}$ for 21 days following inoculation with a $10^{-1}$ soil suspension that had been heated at $55^{\circ} \mathrm{C}$ for $6 \mathrm{~min}$, as described by Okoro et al. (2009). The strain was maintained on modified Bennett's agar (Jones 1949) slopes and as suspensions of hyphal fragments and spores in $20 \%$ (v/v) glycerol at $-80{ }^{\circ} \mathrm{C}$. Biomass for the molecular systematic and most of the chemotaxonomic studies was scraped from 14 day-old modified Bennett's agar plates incubated at $28{ }^{\circ} \mathrm{C}$ and washed twice in distilled water; biomass for most of the chemotaxonomic analyses was freeze-dried and that for the molecular systematic work stored at $-20{ }^{\circ} \mathrm{C}$. Cells for the fatty acid analysis were harvested from yeast extract-malt extract broth (International Streptomyces Project [ISP] medium 2; Shirling and Gottlieb 1966) after 3 days at $25^{\circ} \mathrm{C}$.

\section{Chemotaxonomy and morphology}

Isolate $\mathrm{C} 34^{\mathrm{T}}$ was examined for chemotaxonomic and morphological properties considered to be typical of the genus Streptomyces (Kämpfer 2012). The arrangement of aerial hyphae and spore chains were observed on oatmeal agar (ISP medium 3; Shirling and Gottlieb 1966) after 14 days at $28{ }^{\circ} \mathrm{C}$, using the coverslip technique described by Kawato and Shinobu (1959). Spore chain morphology and spore surface ornamentation were detected by examining gold-coated, dehydrated specimens taken from the oatmeal agar plate, by using an electron microscope (Cambridge Stereoscan 240 instrument) and the procedure 
described by O'Donnell et al. (1993). Cultural characteristics of the isolate were determined using ISP media (Shirling and Gottlieb 1966) following incubation at $28{ }^{\circ} \mathrm{C}$ for 14 days. Standard protocols were used to detect the isomers of diaminopimelic acid (Hasegawa et al. 1983), menaquinones (Collins et al. 1985) and whole organism sugars (Hasegawa et al. 1983). Cellular fatty acids were extracted, methylated and analysed by gas chromatography (Hewlett Packard, model 6890) following the recommended procedure of the Sherlock Microbial Identification System (MIDI, Sasser 1990). The resultant fatty acid methyl esters were identified and quantified using the MIDI ACTINO 1 database (version 6.10).

Phylogenetic analyses

Genomic DNA was extracted from isolate $\mathrm{C} 34^{\mathrm{T}}$ biomass and PCR-mediated amplification of a $16 \mathrm{~S}$ rRNA purified gene product was achieved, as described by Kim and Goodfellow (2002). The resultant almost complete $16 \mathrm{~S}$ rRNA gene sequence $(1,416$ nucleotides [nt]) was submitted to the EzTaxon-e server (http:// eztaxon-e.ezbiocloud.net/; Kim et al. 2012) and aligned with corresponding 16S rRNA gene sequences of the type strains of the most closely related Streptomyces species using CLUSTAL W version 1.8 software (Thompson et al. 1994). Phylogenetic trees were generated from the aligned sequences using the maximumlikelihood (Felsenstein 1981), maximum-parsimony (Fitch 1971) and neighbour-joining (Saitou and Nei 1987) algorithms drawn from the MEGA 5 and PHYML software packages (Guindon and Gascuel 2003; Tamura et al. 2011); an evolutionary distance matrix for the neighbour-joining analysis was prepared using the Jukes and Cantor (1969) model. The topology of the inferred evolutionary trees was evaluated by bootstrap analyses (Felsenstein 1985) based on 1,000 resamplings of the neighbour-joining dataset using MEGA 5 software. The root positions of unrooted trees were estimated using the sequence of Streptomyces albus subsp. albus DSM $40313^{\mathrm{T}}$ (GenBank accession number AJ 621602).

Phenotypic tests

Isolate $\mathrm{C} 34^{\mathrm{T}}$ was examined for a broad range of biochemical, degradative and physiological properties using media and methods described by Williams et al. (1983) and known to be of value in the systematics of streptomycetes (Kämpfer 2012). The enzyme profile of the strain was determined using API ZYM strips (BioMerieux) and its ability to use a broad range of carbon sources determined using Biolog GEN III Micro Plates, in each case following the manufacturer's instructions; a standard inoculum equivalent to 5.0 on the McFarland scale (Murray et al. 1999) was used to inoculate both the microplates and the API ZYM strips. All of the tests were carried out in duplicate.

Generation of whole-genome sequence of isolate $\mathrm{C} 34^{\mathrm{T}}$ and genome analysis

The isolate was grown on tryptone soya broth supplemented with $10 \%$ sucrose-yeast extract-malt extract medium (1:1, v/v) with $5 \mathrm{mM} \mathrm{MgCl}_{2}$ and $0.5 \%$ glycine at $30{ }^{\circ} \mathrm{C}$ for $48 \mathrm{~h}$. Cells were resuspended in $10 \mathrm{mM} \mathrm{NaCl}, 20 \mathrm{mM}$ Tris- $\mathrm{HCl}$ (pH 8.0), $1 \mathrm{mM}$ EDTA and incubated with lysozyme at $37{ }^{\circ} \mathrm{C}$ for 1 to $30 \mathrm{~min}$ until they were lysed. SDS $(0.5 \%$ final concentration) and proteinase $\mathrm{K}(40 \mu \mathrm{g})$ were added and the cell extract incubated at $50{ }^{\circ} \mathrm{C}$ for $6 \mathrm{~h}$ when a standard phenol/chloroform extraction was performed on the lysate. The extract was adjusted to $0.3 \mathrm{M}$ sodium acetate (pH 5.5) and DNA was spooled with a glass rod upon addition of 2 volumes of $96 \%$ ethanol. After washing and drying, the DNA was dissolved in TE buffer. DNA quality was verified by Sall digestion and agarose gel electrophoresis.

Illumina/Solexa sequencing on Genome Analyzer IIx was outsourced (ServiceSX, Leiden, The Netherlands) and 100-nt paired-end-reads were obtained. The quality of the short reads was verified using FastQC (http://www.bioinformatics.bbsrc.ac.uk/projects/fastqc/) and, depending on the quality, reads were trimmed at various lengths at both ends. Processed raw reads were then used as input for the Velvet assembly algorithm (Zerbino and Birney 2008). The genome was annotated using the RAST server (Aziz et al. 2008) with default options. Predictions of gene clusters for natural products were performed using antiSMASH (Medema et al. 2011). The genome sequence has been deposited at DDBJ/EMBL/GenBank under the accession number AZSD0000000.

\section{Multilocus Sequence Analysis}

Multilocus sequence analysis was based on the methods of Guo et al. (2008), Rong et al. (2009), Labeda (2011) 
and Rong and Huang $(2010,2012)$. Genomic DNA was isolated from the strains listed in Table 1 using UltraClean ${ }^{\circledR}$ microbial DNA isolation kits (MoBio Labs, Carlsbad, CA, USA) following the instructions of the manufacturer. Partial sequences of the house-keeping genes atpD (ATP synthase F1, beta subunit), gyrB (DNA gyrase B subunit) and $r p o B$ (RNA polymerase beta subunit) were amplified and sequenced using the primers and protocols described previously by Guo et al. (2008) and Rong et al. (2009) as well as modified primers designed to optimise amplification and sequencing of the house-keeping genes recA (recombinase A) and $\operatorname{trp} B$ (tryptophan synthetase, beta subunit) for a broader range of Streptomyces species (Labeda et al. 2014). Amplified products were purified using ExoSAP-IT (Affymetrix, Santa Clara, CA, USA) and sequenced using BigDye 3.1 on an ABI model 3730 sequencer in the National Center for Agricultural Utilization Research (NCAUR) core sequencing facility. Sequence data for the 5 house-keeping loci for each strain were deposited in Genbank with the accession numbers shown in Table 1. House-keeping gene sequences for species of the genus Streptomyces were organized using Bacterial Isolate Genomic Sequence Database (BIGSdb) version 1.6.3 (Jolley and Maiden 2010) on the ARS Microbial Genomic Sequence Database server at http://199.133.98.43. The alleles of the house-keeping loci for strain $\mathrm{C} 34^{\mathrm{T}}$ were found within the draft genome using the genome sequence scan function in BIGSdb. The alleles were tagged within the genome sequence and added to the sequence database. The sequences of the loci for each strain were concatenated head to tail and exported in FASTA format, providing a dataset of 172 strains and 2,575 positions. Sequences were aligned using MUSCLE (Edgar 2004) and phylogenetic relationships constructed in MEGA 5.2 (Tamura et al. 2011) using maximum-likelihood based on the General Time Reversible model (Nei and Kumar 2000), determined to be the optimal model for these data using jmodeltest2 (Darriba et al. 2012; Guindon and Gascuel 2003). The phylogenetic relationships of the strains were also determined using maximum-parsimony and neighbour-joining analyses. MLSA evolutionary distances were determined using MEGA 5.2 to calculate the Kimura 2-parameter distance (Kimura 1980).

Table 1 Streptomyces strains house-keeping gene sequences deposited for the present study

\begin{tabular}{|c|c|c|c|c|c|c|}
\hline Species & Strain & $a t p D$ & gyrB & recA & гров & $\operatorname{trp} B$ \\
\hline S. leeuwenhoekii & NRRL B-24963 ${ }^{\mathrm{T}}\left(=\mathrm{DSM} 42122^{\mathrm{T}}\right)$ & KJ137029 & KJ137046 & KJ137063 & KJ137080 & KJ137097 \\
\hline S. chryseus & NRRL B-12347 ${ }^{\mathrm{T}}$ & KJ137020 & KJ137037 & KJ137054 & KJ137071 & KJ137088 \\
\hline S. daghestanicus & NRRL B-5418 ${ }^{\mathrm{T}}$ & KJ137021 & KJ137038 & KJ137055 & KJ137072 & KJ137089 \\
\hline S. fimbriatus & NRRL B-3175 & KJ137022 & KJ137039 & KJ137056 & KJ137073 & KJ137090 \\
\hline S. fumanus & NRRL B- $3898^{\mathrm{T}}$ & KJ137023 & KJ137040 & KJ137057 & KJ137074 & KJ137091 \\
\hline S. fumigatiscleroticus & NRRL B-3856 ${ }^{\mathrm{T}}$ & KJ137024 & KJ137041 & KJ137058 & KJ137075 & KJ137092 \\
\hline S. ghanaensis & NRRL B-12104 ${ }^{\mathrm{T}}$ & KJ137025 & KJ137042 & KJ137060 & KJ137076 & KJ137093 \\
\hline S. glaucus & NRRL B-16368 & KJ137026 & KJ137043 & KJ137059 & KJ137077 & KJ137094 \\
\hline S. griseomycini & NRRL B-5421 ${ }^{\mathrm{T}}$ & KJ137027 & KJ137044 & KJ137061 & KJ137078 & KJ137095 \\
\hline S. hirsutus & NRRL B-2713 ${ }^{\mathrm{T}}$ & KJ137028 & KJ137045 & KJ137062 & KJ137079 & KJ137096 \\
\hline S. lusitanus & NRRL B-5637 ${ }^{\mathrm{T}}$ & KJ196366 & KJ196368 & KJ196370 & KJ196372 & KJ196374 \\
\hline S. mexicanus & NRRL B-24196 ${ }^{\mathrm{T}}$ & KJ137030 & KJ137047 & KJ137064 & KJ137081 & KJ137098 \\
\hline S. parvulus & NRRL B-1628 ${ }^{\mathrm{T}}$ & KJ196367 & KJ196369 & KJ196371 & KJ196373 & KJ196374 \\
\hline S. recifensis & NRRL B-3811 ${ }^{\mathrm{T}}$ & KJ137031 & KJ137048 & KJ137065 & KJ137082 & KJ137099 \\
\hline S. seoulensis & NRRL B-24310 & KJ137032 & KJ137049 & KJ137066 & KJ137083 & KJ137100 \\
\hline S. thermocoprophilus & NRRL B-24314 ${ }^{\mathrm{T}}$ & KJ137033 & KJ137050 & KJ137067 & KJ137084 & KJ137101 \\
\hline S. thermodiastaticus & NRRL B-5316 ${ }^{\mathrm{T}}$ & KJ137034 & KJ137051 & KJ137068 & KJ137085 & KJ137102 \\
\hline S. thermovulgaris & NRRL B-12375 & KJ137035 & KJ137052 & KJ137069 & KJ137086 & KJ137103 \\
\hline S. thermovulgaris & NRRL B-12375 & KJ137036 & KJ137053 & KJ137070 & KJ137087 & KJ137104 \\
\hline
\end{tabular}




\section{Results and discussion}

The new bioactive ansamycin-type polyketides, the chaxamycins, and the novel 22-membered macrolactin polyketides, the chaxalactins, produced by Streptomyces strain $\mathrm{C} 34^{\mathrm{T}}$ were named after the Laguna Chaxa soil sampling site in the Atacama Desert (Bull and Asenjo 2013). The chaxamycins display promising antibacterial and antitumour activity while the chaxalactins are active against Gram-positive bacteria. The importance of naming such potentially significant Streptomyces strains is often overlooked despite remarkable improvements in the classification of the genus Streptomyces (Labeda et al. 2012; Kämpfer 2012) aided by standard adherence to the Rules of Nomenclature (Whitman 2011).

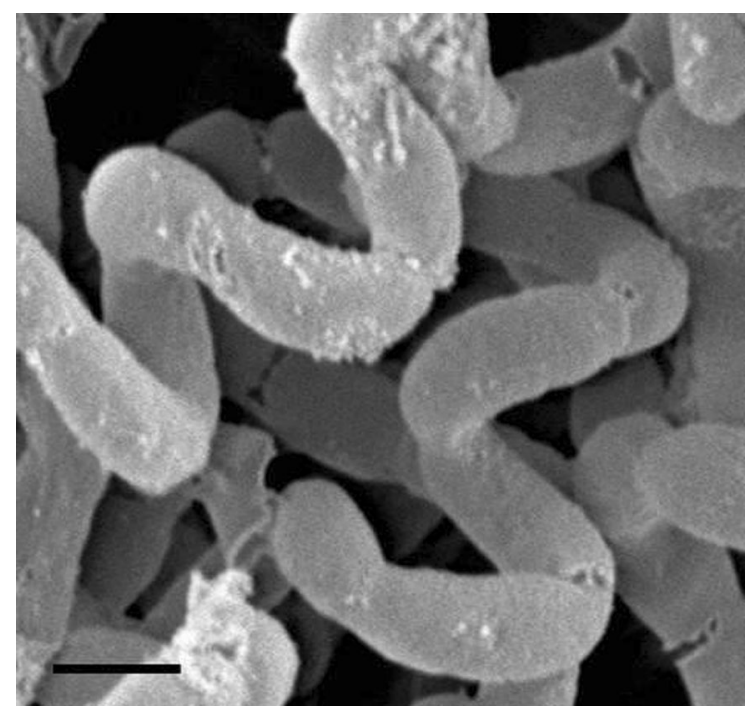

Fig. 1 Scanning electron micrograph of isolate $\mathrm{C} 34^{\mathrm{T}}$ on oatmeal agar after 14 days at $28^{\circ} \mathrm{C}$ showing open spiral chains of smooth surface spores. Bar $1 \mu \mathrm{m}$
The organism was shown to have an extensively branched substrate mycelium which supported aerial hyphae that were seen to differentiate into smooth surfaced spores carried in open spiral chains (Fig. 1). The strain was found to grow well on all of the ISP media on which it was shown to produce a range of aerial spore mass, substrate mycelia and diffusible pigments (Table 2). Whole-organism hydrolysates of the strain were found to be rich in LL-diaminopimelic acid and major amounts of glucose and xylose; the predominant isoprenologues were determined to be hexa- and octa- hydrogenated menaquinones with nine isoprene units in a ratio of 1:4. The cellular fatty acid profile of the strain was shown to consist of major proportions of $(>10 \%)$ anteiso- $\mathrm{C}_{15: 0}(29.2 \%)$, iso$\mathrm{C}_{16: 0}(12.5 \%), \mathrm{C}_{16: 0}(19.1 \%)$ and anteiso- $\mathrm{C}_{17: 0}$ $(13.8 \%)$, lower proportions $(>1.0 \%)$ of iso- $\mathrm{C}_{14: 0}$ $(4.3 \%), \mathrm{C}_{14: 0}(1.1 \%)$, iso-C $\mathrm{C}_{15: 0}(5.5 \%)$, iso- $\mathrm{C}_{17: 1 \omega} 9 \mathrm{c}$

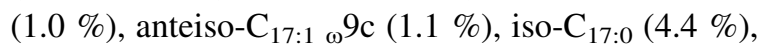
$\mathrm{C}_{17: 0}(3.5 \%)$, iso-C18:0 (0.9 \%) and summed features $\mathrm{C}_{16: 1 \omega} 7 \mathrm{c} / \mathrm{C}_{16: 1} \omega 6 \mathrm{c}(0.9 \%)$ plus trace amounts of other components $(>0.5 \%)$. The chemotaxonomic and morphological properties of isolate $\mathrm{C} 34^{\mathrm{T}}$ were seen to be consistent with its classification in the genus Streptomyces (Kämpfer 2012). The genomic G+C content of the strain was $72.6 \%$, in line with that of other streptomycete genomes.

When the almost complete 16S rRNA gene sequence of strain $\mathrm{C} 34^{\mathrm{T}}$ (GenBank accession number KF 733382) was compared with corresponding sequences of its most immediate phylogenetic neighbours using the EzTaxon e-cloud webtool it was found to be most closely related to the type strains of Streptomyces mexicanus (98.21\%), Streptomyces hyderabadensis $(98.20 \%)$ and Streptomyces chiangmaiensis $(97.87 \%)$. When the 16S rRNA gene sequence

Table 2 Growth and cultural characteristics of strain $\mathrm{C} 34^{\mathrm{T}}$ on standard agar media after incubation for 14 days at $28{ }^{\circ} \mathrm{C}$

\begin{tabular}{lllll}
\hline Media & Growth & Substrate mycelium colour & Aerial spore mass colour & Diffusible pigment \\
\hline Glycerol-asparagine agar (ISP 5) & +++ & Yellowish white & Olivaceous gray green & None \\
Inorganic salts-starch agar (ISP 4) & +++ & Yellowish white & Olivaceous gray green & Yellowish \\
Oatmeal agar (ISP 3) & ++++ & Yellowish white & Olivaceous gray green & Yellowish \\
Peptone-yeast extract-iron agar (ISP 6) & +++ & Gray yellow & Olivaceous gray green & Gray yellow \\
Tryptone-yeast extract agar (ISP 1) & +++ & Yellowish white & Olivaceous gray green & None \\
Tyrosine agar (ISP 7) & +++ & Yellowish white & Olivaceous gray green & Yellowish \\
Yeast extract-malt extract agar (ISP 2) & ++++ & Gray yellow & Gray yellowish green & Pale yellow \\
\hline
\end{tabular}

++++ abundant growth; +++ very good growth 


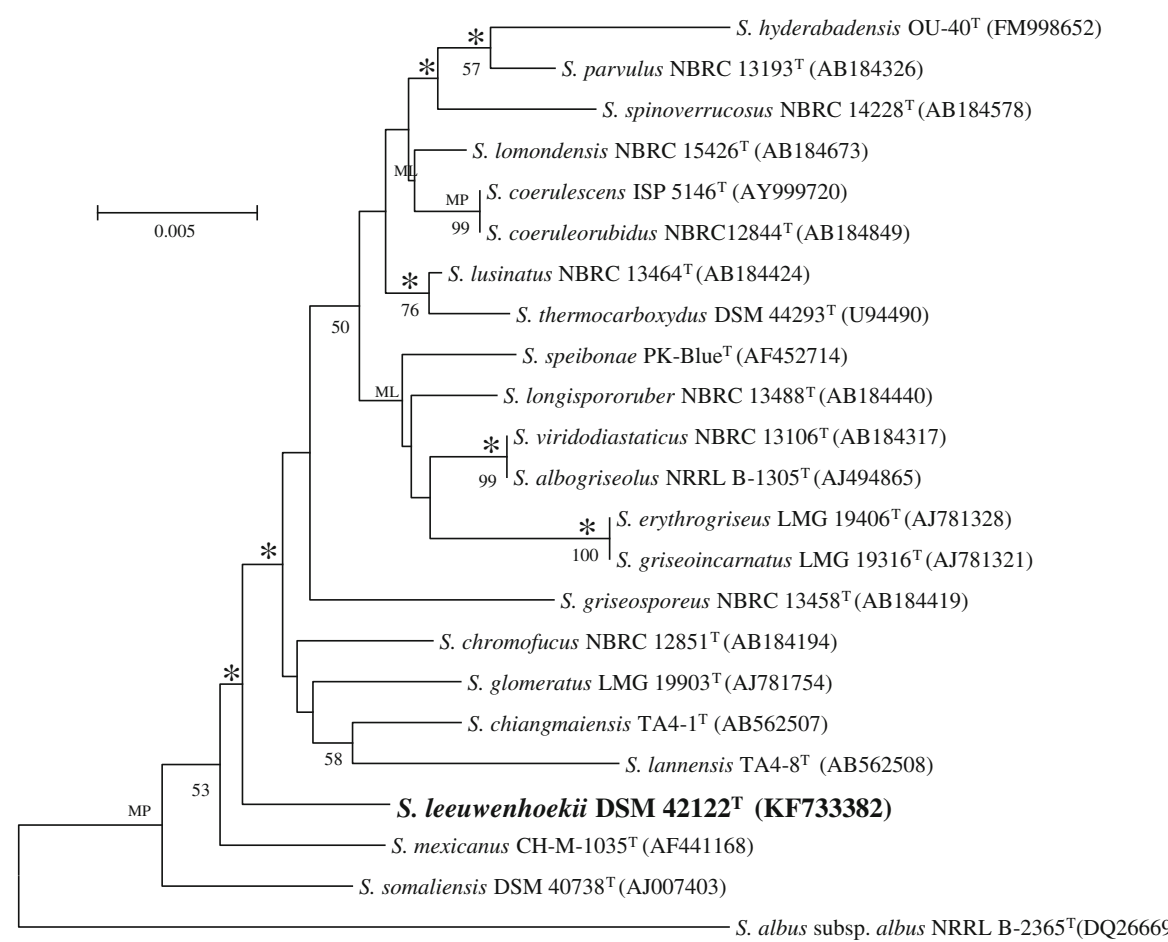

Fig. 2 Neighbour-joining tree based on 16S rRNA gene sequences (1384-1390 sites used) showing relationships between strain $\mathrm{C} 34^{\mathrm{T}}$ and the type strains of closely related Streptomyces species. Asterisks indicate branches of the tree that were also found using the maximum-likelihood and maximumparsimony tree-making algorithms. $M L$ and $M P$ indicate nodes that were recovered using the maximum-likelihood and

of strain $\mathrm{C} 34^{\mathrm{T}}$ was compared with the sequences of its 20 nearest neighbours it was shown to form a distinct phyletic line, the position of which varied depending on which of the tree-making algorithms were used (Fig. 2). In this extended analysis strain $\mathrm{C} 34^{\mathrm{T}}$ was found to be related, albeit loosely, to several of its nearest phylogenetic neighbours, notably to the type strains of S. chiangmaiensis $(98.77 \%, 17 \mathrm{nt}$ differences), S. lusitanus (98.70\%, $18 \mathrm{nt}$ differences), $S$. mexicanus $(98.77 \%, 17 \mathrm{nt}$ differences) and S. parvulus (98.63\%, $19 \mathrm{nt}$ differences). The 16S rRNA gene sequence similarities between strain $\mathrm{C} 34^{\mathrm{T}}$ and the remaining strains in Fig. 1 were shown to be within the range of 98.05-98.56\%, values that corresponded to between 27 and $20 \mathrm{nt}$ differences.

The phylogenetic relationships of strain $\mathrm{C} 34^{\mathrm{T}}$ to other Streptomyces species based on analysis of a sequence alignment resulting from concatenation of 5 house-keeping genes head to tail can be seen in Fig. 3 maximum-parsimony tree-making algorithms, respectively. Numbers at the nodes are percentage bootstrap values based on a neighbour-joining analysis of 1,000 sampled datasets, only values above $50 \%$ are given. The root position of the tree was determined using Streptomyces albus subsp. albus DSM $40313^{\mathrm{T}}$. Bar 0.005 substitutions per nucleotide position

and in the expanded version of this tree (Fig S.1a-c). Strain $\mathrm{C} 34^{\mathrm{T}}$ is not phylogenetically near to any Streptomyces species for which sequences of the house-keeping loci are available, but appears to be most closely related to Streptomyces thermocoprophilus NRRL B-24314 ${ }^{\mathrm{T}}$ based on the present analysis. This relationship is not supported by significant bootstrap values nor by the stability of the relationship when different phylogenetic algorithms are used, such as maximum-parsimony and neighbour-joining analyses. MLSA evolutionary distances were determined using MEGA 5.2 to calculate the Kimura 2-parameter distance (1980) as shown in Table 3. Strain C34 $\left(=\right.$ NRRL B-24963 $\left.{ }^{\mathrm{T}}\right)$ exhibited an MLSA distance greater than 0.007 with all of the phylogenetically near species, supporting the proposal that this strain represents a new species since the guideline empirically determined by Rong and Huang (2012) states this distance equates to $70 \%$ DNA-DNA homology. 


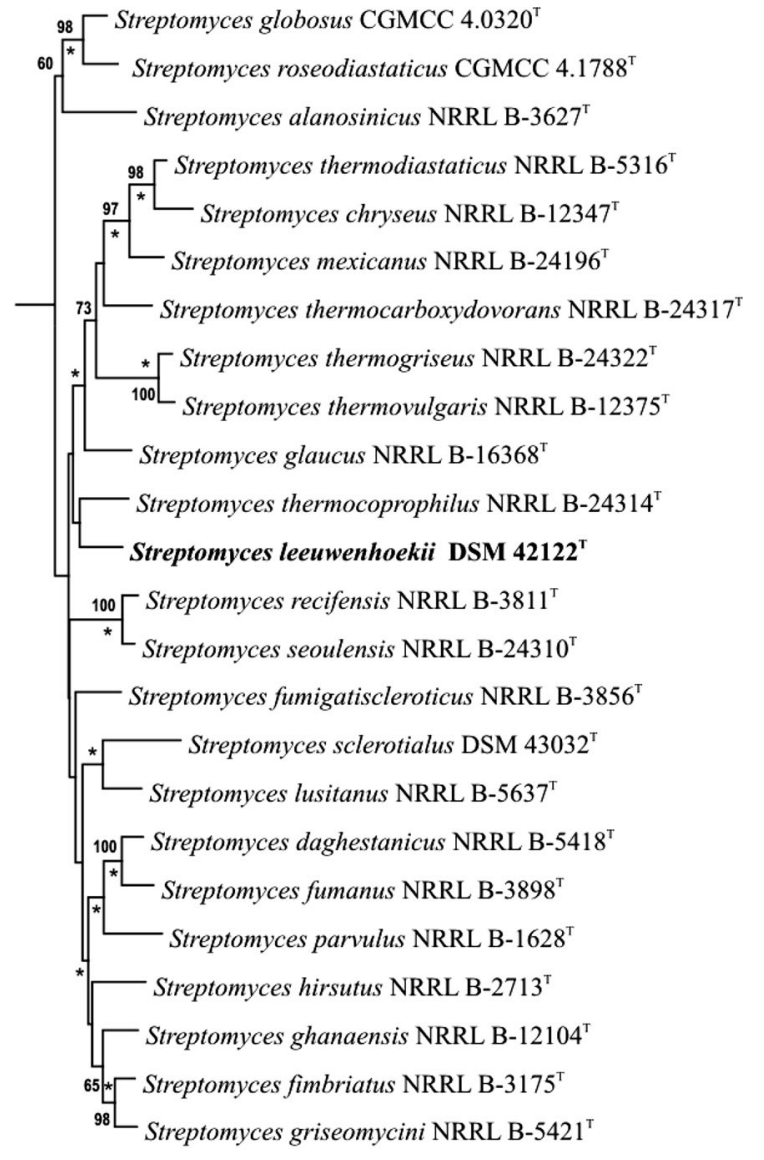

0.1

Fig. 3 Subtree from the phylogenetic tree inferred from concatenated partial sequences of the house-keeping genes $a t p D, \operatorname{gr} B, \operatorname{rec} A, \mathrm{rpoB}$ and $\operatorname{trp} B$ in MEGA 5.2 (Tamura et al. 2011) using the maximum likelihood method based on the General Time Reversible model (Nei and Kumar 2000). There were 2,575 positions and 152 strains in the final dataset. Trees were also inferred using the Tamura and Nei evolutionary distance method (1993) with the neighbour-joining algorithm of Saitou and Nei (1987) neighbour-joining and maximum parsimony models in MEGA 5.2 and conserved branches in all methods are marked with an asterisk. Percentages at the nodes represent levels of bootstrap support from 1,000 resampled datasets (Felsenstein 1985) with values less than $60 \%$ not shown. The proposed new species Streptomyces leeuwenhoekii DSM $42122^{\mathrm{T}}$ is indicated with a bold node label. Bar marker equals number of substitutions per site

DNA:DNA hybridisation (DDH) studies were not carried out between strain $\mathrm{C} 34^{\mathrm{T}}$ and its nearest phylogenetic neighbours as the $16 \mathrm{~S}$ rRNA gene similarities with the latter are well below the $99.0 \%$ similarity level recommended to trigger the need for
DDH experiments between closely related actinomycetes (Meier-Kolthoff et al. 2013). This point is reinforced by the fact that type strains of many Streptomyces species with higher $16 \mathrm{~S}$ rRNA gene similarities $(>99.3 \%)$ than those recorded between strain $\mathrm{C} 34^{\mathrm{T}}$ and its closest phylogenetic neighbours, have DDH similarity values well below the $70 \%$ cut off point recommended for the delineation of bacterial species (Wayne et al. 1987); examples include strains recovered from several habitats, including ones isolated from the Atacama Desert (Santhanam et al. 2012a, b, 2013). Indeed, it seems likely that the position of strain $\mathrm{C} 34^{\mathrm{T}}$ and its closest neighbours in the Streptomyces 16S rRNA gene tree will only be stabilised by the addition of nucleotide sequences of more validly named species to this part of the tree, as indicated by the assignment of strain $\mathrm{C} 34^{\mathrm{T}}$ and other Atacama Desert streptomycetes to a well defined Streptomyces subclade (Okoro et al. 2009).

Identical results were obtained between the duplicated cultures of strain $\mathrm{C} 34^{\mathrm{T}}$ for all of the phenotypic tests. The organism was shown to exhibit a broad range of phenotypic properties as cited in the species description and in Table 4. Some of these properties, notably the morphological and cultural features, were found to be of particular value in distinguishing between Streptomyces species by Labeda et al. (2012) in their phylogenetic study of Streptomycetaceae species. Comparison of some of these properties with corresponding results reported for S. chiangmaiensis (Promnuan et al. 2013) and S. hyderabadensis (Reddy et al. 2011) showed these strains could be distinguished readily (Table 4). Further, $\mathrm{C} 34^{\mathrm{T}}$, unlike the type strains of $S$. chiangmaiensis and S. hyderabadensis, produced diffusible pigments on inorganic saltstarch, oatmeal and tyrosine agars (Reddy et al. 2011; Promnuan et al. 2013). It can also be separated from the $S$. hyderabadensis strain by its capacity to degrade casein and xylan and its inability to degrade hypoxanthine and hydrolyse urea.

Full genome sequencing of strain $\mathrm{C} 34^{\mathrm{T}}$ (GenBank accession number AZSD0000000) using Illumina methods led to an assembly of 658 contigs for a total genome size of $7.86 \mathrm{Mb}$, predicted to encode 77 RNAs and 6,780 proteins. The functions of the genes were catalogued into different functional classes (Fig. 4). The relative distribution of the different classes is similar to that of the model strains $S$. coelicolor A3(2) (Bentley et al. 2002) and S. lividans 66 (Cruz-Morales 
Table 3 MLSA distance for strains phylogenetically near to S. leeuwenhoekii NRRL B-24963 ${ }^{\mathrm{T}}$ (values in bold text)

\begin{tabular}{|c|c|c|c|c|c|c|c|c|c|c|c|c|}
\hline \multirow{2}{*}{$\begin{array}{l}\text { Strain } \\
\text { S. albus NRRL B-1811 }\end{array}$} & \multicolumn{12}{|c|}{ MLSA (Kimura 2-parameter) distance } \\
\hline & - & & & & & & & & & & & \\
\hline $\begin{array}{l}\text { S. thermocarboxydovorans } \\
\text { NRRL_B- } 24317^{\mathrm{T}}\end{array}$ & 0.141 & & & & & & & & & & & \\
\hline $\begin{array}{l}\text { S. thermocoprophilus NRRL } \\
\text { B- } 24314^{\mathrm{T}}\end{array}$ & 0.136 & 0.073 & & & & & & & & & & \\
\hline $\begin{array}{l}\text { S. thermodiastaticus NRRL } \\
\text { B-5316 }\end{array}$ & 0.148 & 0.063 & 0.074 & & & & & & & & & \\
\hline $\begin{array}{l}\text { S. thermogriseus NRRL } \\
\text { B- } 24322^{\mathrm{T}}\end{array}$ & 0.137 & 0.071 & 0.073 & 0.073 & & & & & & & & \\
\hline $\begin{array}{l}\text { S. thermovulgaris NRRL } \\
\text { B- } 12375^{\mathrm{T}}\end{array}$ & 0.138 & 0.075 & 0.075 & 0.069 & 0.020 & & & & & & & \\
\hline S. sclerotialus DSM $43032^{\mathrm{T}}$ & 0.145 & 0.086 & 0.084 & 0.089 & 0.096 & 0.098 & & & & & & \\
\hline S. globosus CGMCC $4.0320^{\mathrm{T}}$ & 0.145 & 0.070 & 0.053 & 0.066 & 0.071 & 0.075 & 0.078 & & & & & \\
\hline $\begin{array}{l}\text { S. roseodiastaticus CGMCC } \\
4.1788^{\mathrm{T}}\end{array}$ & 0.140 & 0.069 & 0.063 & 0.065 & 0.076 & 0.069 & 0.088 & 0.037 & & & & \\
\hline S. alanosinicus NRRL B-3627 & 0.139 & 0.088 & 0.073 & 0.095 & 0.089 & 0.092 & 0.090 & 0.065 & 0.068 & & & \\
\hline $\begin{array}{l}\text { S. leeuwenhoekii NRRL } \\
\text { B- } 24963^{\mathrm{T}}\end{array}$ & 0.146 & 0.062 & 0.054 & 0.073 & 0.076 & 0.082 & 0.071 & 0.061 & 0.069 & 0.070 & & \\
\hline S. chryseus NRRL B-12347 & 0.141 & 0.066 & 0.078 & 0.032 & 0.077 & 0.072 & 0.086 & 0.076 & 0.070 & 0.095 & 0.076 & \\
\hline S. daghestanicus NRRL B-5418 & 0.129 & 0.063 & 0.060 & 0.068 & 0.078 & 0.080 & 0.081 & 0.063 & 0.065 & 0.074 & 0.053 & 0.071 \\
\hline S.. fimbriatus NRRL B-3175 & 0.141 & 0.060 & 0.047 & 0.067 & 0.075 & 0.075 & 0.076 & 0.054 & 0.065 & 0.076 & 0.042 & 0.069 \\
\hline S. fumanus NRRL B- $3898^{\mathrm{T}}$ & 0.134 & 0.072 & $0.069 \backslash 8$ & 0.070 & 0.087 & 0.088 & 0.080 & 0.065 & 0.072 & 0.080 & 0.061 & 0.078 \\
\hline $\begin{array}{l}\text { S. fumigatiscleroticus NRRL } \\
\text { B- } 3856^{\mathrm{T}}\end{array}$ & 0.134 & 0.069 & 0.062 & 0.073 & 0.076 & 0.077 & 0.070 & 0.055 & 0.065 & 0.070 & 0.056 & 0.075 \\
\hline S. ghanaensis NRRL B-12104 ${ }^{\mathrm{T}}$ & 0.143 & 0.063 & 0.065 & 0.073 & 0.080 & 0.080 & 0.077 & 0.059 & 0.070 & 0.075 & 0.060 & 0.078 \\
\hline S. glaucus NRRL B-16368 ${ }^{\mathrm{T}}$ & 0.138 & 0.062 & 0.060 & 0.066 & 0.076 & 0.070 & 0.082 & 0.064 & 0.054 & 0.083 & 0.055 & 0.067 \\
\hline S. griseomycini NRRL B-5421 ${ }^{\mathrm{T}}$ & 0.144 & 0.056 & 0.055 & 0.064 & 0.075 & 0.077 & 0.069 & 0.058 & 0.063 & 0.074 & 0.041 & 0.071 \\
\hline S. hirsutus NRRL B- $2713^{\mathrm{T}}$ & 0.152 & 0.072 & 0.069 & 0.083 & 0.084 & 0.085 & 0.076 & 0.072 & 0.072 & 0.085 & 0.064 & 0.082 \\
\hline S. lusitanus NRRL B-5637 ${ }^{\mathrm{T}}$ & 0.135 & 0.070 & 0.069 & 0.081 & 0.083 & 0.087 & 0.069 & 0.068 & 0.077 & 0.147 & 0.065 & 0.084 \\
\hline S. mexicanus NRRL B-24196 & 0.147 & 0.065 & 0.068 & 0.042 & 0.077 & 0.074 & 0.083 & 0.059 & 0.055 & 0.086 & 0.066 & 0.060 \\
\hline S. parvulus NRRL B-1628 ${ }^{\mathrm{T}}$ & 0.134 & 0.079 & 0.075 & 0.083 & 0.085 & 0.088 & 0.077 & 0.083 & 0.085 & 0.083 & 0.072 & 0.085 \\
\hline S. recifensis NRRL B-3811 ${ }^{\mathrm{T}}$ & 0.146 & 0.078 & 0.066 & 0.073 & 0.083 & 0.087 & 0.085 & 0.058 & 0.066 & 0.087 & 0.073 & 0.080 \\
\hline S. seoulensis NRRL B- $24310^{\mathrm{T}}$ & 0.146 & 0.078 & 0.064 & 0.073 & 0.083 & 0.086 & 0.082 & 0.061 & 0.068 & 0.087 & 0.069 & 0.079 \\
\hline S. daghestanicus NRRL B-5418 & - & & & & & & & & & & & \\
\hline S.. fimbriatus NRRL B- $3175^{\mathrm{T}}$ & 0.058 & & & & & & & & & & & \\
\hline S. fumanus NRRL B- $3898^{\mathrm{T}}$ & 0.034 & 0.058 & & & & & & & & & & \\
\hline 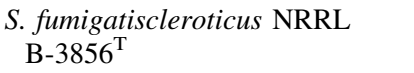 & 0.058 & 0.044 & 0.055 & & & & & & & & & \\
\hline S. ghanaensis NRRL B-12104 ${ }^{\mathrm{T}}$ & 0.052 & 0.040 & 0.052 & 0.053 & & & & & & & & \\
\hline S. glaucus NRRL B-16368 & 0.060 & 0.047 & 0.064 & 0.061 & 0.060 & & & & & & & \\
\hline S. griseomycini NRRL B-5421 ${ }^{\mathrm{T}}$ & 0.056 & 0.027 & 0.059 & 0.050 & 0.042 & 0.057 & & & & & & \\
\hline S. hirsutus NRRL B-2713 & 0.060 & 0.051 & 0.062 & 0.063 & 0.052 & 0.068 & 0.053 & & & & & \\
\hline S. lusitanus NRRL B-5637 ${ }^{\mathrm{T}}$ & 0.058 & 0.060 & 0.060 & 0.057 & 0.054 & 0.072 & 0.059 & 0.065 & & & & \\
\hline S. mexicanus NRRL B-24196 ${ }^{\mathrm{T}}$ & 0.067 & 0.058 & 0.070 & 0.064 & 0.066 & 0.064 & 0.061 & 0.076 & 0.071 & & & \\
\hline S. parvulus NRRL B-1628 ${ }^{\mathrm{T}}$ & 0.054 & 0.066 & 0.061 & 0.070 & 0.064 & 0.066 & 0.066 & 0.063 & 0.060 & 0.079 & & \\
\hline S. recifensis NRRL B-3811 ${ }^{\mathrm{T}}$ & 0.069 & 0.067 & 0.070 & 0.066 & 0.075 & 0.073 & 0.069 & 0.070 & 0.066 & 0.071 & 0.070 & \\
\hline
\end{tabular}


Table 3 continued

\begin{tabular}{lllllllllllll}
\hline Strain & \multicolumn{1}{c}{ MLSA (Kimura 2-parameter) distance } \\
\hline S. seoulensis NRRL B-24310 & 0.069 & 0.063 & 0.069 & 0.062 & 0.072 & 0.068 & 0.069 & 0.071 & 0.064 & 0.069 & 0.066 & 0.019
\end{tabular}

The distance between all strains is greater than 0.007 which was defined by Rong and Huang (2012) as equivalent to $70 \%$ genomic DNA similarity

Table 4 Phenotypic properties that distinguish strain $\mathrm{C} 34^{\mathrm{T}}$ from the type strains of S. chiangmaiensis and S. hyderabadensis

\begin{tabular}{|c|c|c|c|}
\hline Characteristics & Strain $\mathrm{C} 34^{\mathrm{T}}$ & 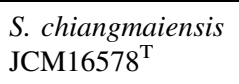 & $\begin{array}{l}\text { S. hyderabadensis } \\
\text { CCTCC-A } 209024^{\mathrm{T}}\end{array}$ \\
\hline Spore chains & Spiral & Spiral & Straight \\
\hline \multicolumn{4}{|c|}{ Growth on yeast extract-malt extract agar (ISP medium2): } \\
\hline Aerial spore mass & Gray yellow green & Bamboo chamois & Gray \\
\hline Substrate mycelium & Gray yellow & None & Brown \\
\hline Diffusible pigment & Pale yellow & Yellow brown & None \\
\hline \multicolumn{4}{|l|}{ Growth on sole carbon } \\
\hline D-Fructose & + & - & - \\
\hline D-Raffinose & - & + & + \\
\hline L-Rhamnose & + & - & - \\
\hline \multicolumn{4}{|l|}{ Growth at/with } \\
\hline $10{ }^{\circ} \mathrm{C}$ & + & - & - \\
\hline $50{ }^{\circ} \mathrm{C}$ & + & - & + \\
\hline pH 10.0 & + & + & - \\
\hline $7.5 \% \mathrm{w} / \mathrm{v} \mathrm{NaCl}$ & + & - & - \\
\hline
\end{tabular}

Data for the type strains of $S$. chiangmaiensis and S. hyderabadensis were taken from Promnuan et al. (2013) and Reddy et al. (2011), respectively

+ positive, - negative

et al. 2013). RAST is a widely used annotation tool that allows good initial prediction of gene functions. However, for a more detailed prediction regarding the specific functions of secondary metabolism-related genes, a dedicated algorithm is required such as antiSMASH (Medema et al. 2011). In particular, the AHBA gene linked to chaxamycin synthesis in strain C $34^{\mathrm{T}}$ (Rateb et al. 2011a) was found by BLAST search among several polyketide synthase (PKS) type 1 genes in a cluster of genes with similarity to genes of the rifamycin biosynthetic pathway (sequence 0641). However, many more PKS gene clusters were identified by antiSMASH (Table S1), including the genes we believe are responsible for the biosynthesis of chaxamycin and chaxalactin.

We recently proposed a new method for the classification of actinomycetes (Girard et al. 2013), based on the conservation of the SsgA-like proteins
(SALPs). The SALPs are a family of cell division regulators that only occur in morphologically complex actinomycetes (Traag and van Wezel 2008), whereby SsgA and SsgB together control division-site selection (Willemse et al. 2011). All actinomycetes contain an SsgB homologue, which shows extremely high conservation within members of the same genus (maximum of one amino-acid change), while high diversity exists even between closely related genera. SsgA is only found in members of the family Streptomycetaceae, and its amino acid sequence contains signatures that allow accurate prediction of its morphology in submerged culture and divides the streptomycetes into two branches: LSp (liquid culture sporulation) and NLSp (no liquid culture sporulation). The presence of Gly53, Cys56, Val66, Leu75, Gln84 and Asp125 in SsgA and the Gln128 in SsgB, classifies strain C34 ${ }^{\mathrm{T}}$ in the NLSp branch (Girard et al. 2013), which indeed 



Fig. 4 Overview of Streptomyces leeuwenhoekii $\mathrm{C} 34^{\mathrm{T}}$ subsystem gene functions as generated by analysis on the RAST server at (http://rast.nmpdr.org)

correlates with the observed phenotype in submerged culture (data not shown).

Strain $\mathrm{C} 34^{\mathrm{T}}$ is only loosely associated with its nearest phylogenetic neighbours based on comparative 16S rRNA gene sequence data and its distinctness is underpinned by corresponding MLSA data based on concatenated sequences of the five house-keeping alleles. It can also be separated readily from the type strains of S. chiangmaiensis and S. hyderabadensis using a broad range of phenotypic properties (Table 4). These data clearly show that strain CT $34^{\mathrm{T}}$ merits species status within the genus Streptomyces. The name proposed for this taxon is Streptomyces leeuwenhoekii sp. nov., the type strain of which, $\mathrm{C} 34^{\mathrm{T}}$, possesses a remarkably large number of gene clusters involved in natural product synthesis (Table S1).

Finally, we venture to suggest that future descriptions of type strains of novel prokaryotic species should include data from whole-genome sequences. This logical extension to the polyphasic taxonomic concept will not only provide "grist to the taxonomic mill” (Klenk and Goker 2010; Sutcliffe et al. 2012; Sentausa and Fournier 2013), as shown in the present study, but will also reveal invaluable insights into the developmental biology, ecology, evolution, physiology and biotechnological potential of prokaryotic species (Gao and Gupta 2012; Chandra and Chater 2014; Girard et al. 2013) and will thereby help revitalize prokaryotic systematics as a fundamental scientific discipline. However, as such developments take hold it is vitally important that the microbiological community per se build upon sound taxonomic practices, not least the nomenclatural type concept (Goodfellow and Fiedler 2010; Jensen 2010; Whitman 2011).

Description of Streptomyces leeuwenhoekii sp. nov.

Streptomyces leeuwenhoekii (leeu.wen.hoek'i.i. N.L. gen. n. leeuwenhoekii, of Leeuwenhoek, named after Antonie van Leeuwenhoek (1632-1723), the father of microbiology).

Aerobic, Gram-positive, catalase-positive actinomycete which forms an extensively branched substrate mycelium that carries aerial hyphae which differentiate into spiral chains of smooth surfaced spores $(0.7-0.9 \times 0.8-1.0 \mu \mathrm{m})$ on oatmeal agar. Yellow diffusible pigments are formed on inorganic salts-starch, oatmeal, tyrosine and yeast extract-malt extract agars. Grows from 4 to $50{ }^{\circ} \mathrm{C}$, optimally $\sim 30{ }^{\circ} \mathrm{C}$, from $\mathrm{pH} 6.0$ to 11 , optimally $\sim 7.0$, and in the presence of $10 \% \mathrm{w} / \mathrm{v}$ sodium chloride. Allantoin and arbutin are hydrolysed, but not aesculin or urea. The strain is positive for acid and alkaline phosphatase, $\alpha$-cystine arylamidase, esterase (C4), esterase lipase (C8), $\alpha$ - and $\beta$-glucosaminidases, lipase (C4), $\mathrm{N}$-acetyl- $\beta$-glucosaminidase, naphthol-AS-B1-phosphatase and valine arylamidase, 
but negative for $\alpha$-chymotrypsin, $\alpha$-fucosidase, $\alpha$ and - $\beta$-glucosidase, $\beta$-glucuronidase and $\alpha$-mannosidase (API-ZYM tests). Degrades elastin, cellulose, guanine, starch, tributyrin, and Tween 40, but not chitin, or Tweens 20 and 60. Assimilates (as sole carbon sources) acetic acid, acetoacetic acid, dextrin, D-fructose-6phosphate, D-galacturonic acid, D-gluconic acid, $\alpha$-and $\beta$ - hydroxybutyric acids, $\alpha$-keto-butyric acid, $\alpha$-keto-glutaric acid, and Tween 30, but not D-arabitol, D-cellobiose, D- and L-fucose, D-galactose, gentiobiose, glycerol, myo-inositol, $\alpha$-D-lactose, D-mannose, D-melibiose, $\alpha$-methyl-D-glucoside, D-salicin, D- and L-serine, D-sorbitol, stachyose, sodium butyrate, D-trehalose and D-turanose. Additional phenotypic properties are cited in the text and in Tables 2 and 4. Chemotaxonomic properties are typical of the genus. Produces novel bioactive secondary metabolites, the chaxalactins and chaxamycins. The DNA G+C composition of the type strain is $72.6 \mathrm{~mol} \%$.

The type strain $\mathrm{C} 34^{\mathrm{T}}$ (= DSM $42122^{\mathrm{T}}$; NRRL $\mathrm{B}-24963^{\mathrm{T}}$ ) was isolated from a hyper-arid soil collected from the Chaxa de Laguna, Salar de Atacama, near Tocanao, Chile. The species description is based on a single strain and hence serves as a description of the type strain. The GenBank accession number for the 16S rRNA gene sequence of strain $\mathrm{C} 34^{\mathrm{T}}$ is $\mathrm{KF} 733382$.

Acknowledgments Kanungnid Busarakam is grateful for a scholarship from the Thai Royal Government, Gilles P. van Wezel for GenExpand Grant No. 10467 from The Netherlands Applied Research Council (STW), Alan T Bull for support from The Royal Society (International Joint Project Grant JP 100654) and Michael Goodfellow for an Emeritus Fellowship from the Leverhulme Trust. The authors are indebted to Dr Byung-Yong Kim for carrying out the fatty acid analysis on the type strain of Streptomyces leeuwenhoekii.

\section{References}

Aziz RK, Bartels D, Best AA, DeJongh M, Disz T, Edwards RA, Formsma K, Gerdes S, Glass EM, Kubal M, Meyer F, Olsen GJ, Olson R, Osterman AL, Overbeek RA, McNeil LK, Paarmann D, Paczian T, Parrello B, Pusch GD, Reich C, Stevens R, Vassieva O, Vonstein V, Wilke A, Zagnitko O (2008) The RAST Server: rapid annotations using subsystems technology. BMC Genom 9:75

Bentley SD, Chater KF, Cerdeno-Tarraga AM et al (2002) Complete genome sequence of the model actinomycete Streptomyces coelicolor A3(2). Nature 417:141-147

Bérdy J (2012) Thought and facts about antibiotics: where are we now and where are we heading. J Antibiot (Tokyo) 51:1-26
Bull AT, Asenjo JA (2013) Microbiology of hyper-arid environments: recent insights from the Atacama Desert. Antonie Van Leeuwenhoek 103:1173-1179

Busti E, Monciardini P, Cavaletti L, Bamonte R, Lazzarini A, Sosio M, Donadio S (2006) Antibiotic-producing ability by representatives of newly discovered lineages of actinomycetes. Microbiology 152:675-683

Chandra G, Chater KF (2014) Developmental biology of Streptomyces from the perspective of 100 actinobacterial gene sequences. FEMS Microbiol Rev. (in press)

Collins MD, Goodfellow M, Minnikin DE, Alderson G (1985) Menaquinone composition of mycolic acid containing actinomycetes and some sporoactinomycetes. J Appl Bacteriol 58:77-86

Cruz-Morales P, Vijgenboom E, Iruegas-Bocardo F et al (2013) The genome sequence of Streptomyces lividans 66 reveals a novel tRNA-dependent peptide biosynthetic system within a metal-related genomic island. Genome Biol Evol 5:1165-1175

Darriba D, Taboada GL, Doallo R, Posada D (2012) jModelTest 2: more models, new heuristics and parallel computing. Nat Methods 9:772

Edgar RC (2004) MUSCLE: multiple sequence alignment with high accuracy and high throughput. Nucleic Acids Res 32:1792-1797

Felsenstein J (1981) Evolutionary trees from DNA sequences: maximum likelihood approach. J Mol Evol 17:368-376

Felsenstein J (1985) Confidence limits on phylogenies: an approach using the bootstrap. Evolution 39:783-791

Fitch WM (1971) Towards defining the course of evolution: minimum change for a specific tree topology. Syst Zool 20:406-416

Gao B, Gupta RS (2012) Phylogenetic framework and molecular signatures for the main clades of the phylum Actinobacteria. Microbiol Mol Biol Rev 76:66-111

Girard G, Traag BA, Sangal V, Mascini N, Hoskisson PA, Goodfellow M, van Wezel GP (2013) A novel taxonomic marker that discriminates between morphologically complex actinomycetes. Open Biol 3:130073

Gómez-Silva B, Rainey FA, Warren-Rhodes KA, Mc Kay CP, Navarro-González R (2008) Atacama Desert soil microbiology. In: Dion P, Nautinal CS (eds) Microbiology of extreme soils, soil biology 13. Springer, Berlin, pp 117-132

Goodfellow M, Fiedler HP (2010) A guide to successful bioprospecting: informed by actinobacterial systematics. Antonie Van Leeuwenhoek 98:119-142

Guindon S, Gascuel O (2003) A simple, fast and accurate algorithm to estimate large phylogenetics by maximum likelihood. Syst Biol 52:696-704

Guo Y, Zheng W, Rong X, Huang Y (2008) A multilocus phylogeny of the Streptomyces griseus 16S rRNA gene clade: use of multilocus sequence analysis for streptomycete systematics. Int J Syst Evol Microbiol 58:149-159

Hasegawa T, Takizawa M, Tanida S (1983) A rapid analysis for chemical grouping of aerobic actinomycetes. J Gen Appl Microbiol 29:319-322

Hohmann C, Schneider K, Bruntner C, Irran E, Nicholson G, Bull AT, Jones AL, Brown R, Stach JEM, Goodfellow M, Beil W, Krämer M, Imhoff JF, Süssmuth RO, Fiedler H-P (2009) Caboxamycin, a new antibiotic of the benzoxazole 
family produced by the deep-sea strain Streptomyces NTK 937. J Antibiot (Tokyo) 62:99-104

Jensen P (2010) Linking species concepts to natural product discovery in the post-genomic era. J Ind Microbiol Biotechnol 37:219-224

Jolley K, Maiden M (2010) BIGSdb: scalable analysis of bacterial genome variation at the population level. BMC Bioinformatics 11:595

Jones KL (1949) Fresh isolates of actinomycetes in which the presence of sporogenous aerial mycelia is a fluctuating characteristic. J Bacteriol 57:141-145

Jukes TH, Cantor CR (1969) Evolution of protein molecules. In: Munro HN (ed) Mammalian protein metabolism. Academic Press, London, pp 21-132

Kämpfer P (2012) Genus I. Streptomyces Waksman and Henrici 1943, 339AL emend. Witt and Stackebrandt 1990, 370, emend. Wellington, Stackebrandt, Sanders, Wolstrup and Jorgensen 1992, 159. In: Goodfellow M, Kämpfer P, Busse H-J, Trujillo ME, Suzuki K-I, Ludwig W, Whitman WB (eds) Bergey's manual of systematic bacteriology, Part B, vol 5, 2nd edn. Springer, New York, pp 1455-1767

Kawato M, Shinobu R (1959) On Streptomyces herbaricolor $\mathrm{sp}$. nov., supplement: a simple technique for microscopical observation. Mem Osaka Univ Lib Arts Educ B Nat Sci 8:114-119

Kim S-B, Goodfellow M (2002) Streptomyces thermospinisporus sp. nov., a moderately thermophilic carboxydotrophic streptomycete isolated from soil. Int J Syst Evol Microbiol 52:1225-1228

Kim O-S, Cho Y-J, Lee K, Yoon S-H, Kim M, Na H, Park S-C, Jeon YS, Lee J-H, Yi H, Won S, Chun J (2012) Introducing ExTaxon-e: a prokaryotic 16S rRNA gene sequence database with phylotypes that represent uncultured species. Int J Syst Evol Microbiol 62:716-721

Kimura M (1980) A simple method for estimating evolutionary rates base substitutions through comparative studies of nucleotide sequences. J Mol Evol 16:111-120

Klenk H-P, Goker G (2010) En route to genomic-based classification of archaea and bacteria. Syst Appl Microbiol 33:175-182

Labeda DP (2011) Multilocus sequence analysis of phytopathogenic Streptomyces species. Int J Syst Evol Microbiol 61:2525-2531

Labeda DP, Goodfellow M, Brown R, Ward AC, Lanoot C, Vanncanneyt M, Swings J, Kim S-B, Liu Z, Chun J, Tamura T, Oguchi A, Kikuchi T, Kikuchi H, Nishii T, Tsuji K, Yamaguchi Y, Tase A, Takahashi M, Sakane T, Suzuki KI, Hatano K (2012) Phylogenetic study of the species within the family Streptomycetaceae. Antonie Van Leeuwenhoek 101:73-104

Labeda DP, Doroghazi JP, Ju K-S, Metcalf WW. (2014) Taxonomic evaluation of Streptomyces albus and related species using multilocus sequence analysis and proposals to emend the description of Streptomyces albus and describe Streptomyces pathocidini sp. nov. Int J Syst Evol Microbiol 64. (in press)

Medema MH, Blin K, Cimermancic P, de Jager V, Zakrzewski P, Fischbach MA, Weber T, Takano E, Breitling R (2011) antiSMASH: rapid identification, annotation and analysis of secondary metabolite biosynthesis gene clusters in bacterial and fungal genome sequences. Nucleic Acids Res 39:W339-W346

Meier-Kolthoff JP, Göker M, Spöer C, Klenk H-P (2013) When should a DDH experiment be mandatory in microbial taxonomy? Arch Microbiol 195:413-418

Murray PR, Baron EJ, Phaller MA, Ternover JC, Yolkken RJ (1999) Manual of clinical microbiology, 7th edn. ASM Press, Washington DC

Nachtigall J, Kulik Helaly S, Bull AT, Goodfellow M, Asenjo JA, Maier A, Wiese J, Inhoff JF, Süssmuth R-D, Fiedler H-P (2011) Atacamycins A-C, 22 membered antitumor macrolide derivatives produced by Streptomyces sp. C38. J Antibiot (Tokyo) 64:775-780

Nei M, Kumar S (2000) Molecular evolution and phylogenetics. Oxford University Press, New York

O'Donnell AG, Falconer C, Goodfellow M, Ward AC, Williams E (1993) Biosystematics and diversity amongst novel carboxydotrophic actinomycetes. Antonie Van Leeuwenhoek 64:325-340

Okoro CK, Brown R, Jones AL, Andrews BA, Asenjo JA, Goodfellow M, Bull AT (2009) Diversity of culturable actinomycetes in hyper-arid soils of the Atacama Desert, Chile. Antonie Van Leeuwenhoek 95:121-133

Promnuan Y, Kudo T, Ohkama M, Chantawannakul P (2013) Streptomyces chiangmaiensis sp. nov. and Streptomyces lannensis sp. nov., isolated from the South-East Asian stingless bee (Tetragonilla collina). Int J Syst Evol Microbiol 63:1896-1901

Rateb ME, Houssen WE, Arnold M, Abdelrahman M-H, Deng H, Harrison WTA, Okoro CK, Asenjo JA, Andrews BA, Ferguson G, Bull AT, Goodfellow M, Ebel R, Jaspars M (2011a) Chaxamycins A-D, bioactive ansamycins from a hyper-arid desert Streptomyces sp. J Nat Prod 74:1965-1971

Rateb ME, Houssen WE, Harrison WT, Deng H, Okoro CK, Asenjo JA, Andrews BA, Bull AT, Goodfellow M, Ebel R, Jaspars M (2011b) Diverse metabolic profiles of a Streptomyces strain isolated from a hyper-arid environment. J Nat Prod 74:1491-1499

Reddy TV, Mahmood S, Paris L, Reddy YH, Wellington EMH, Idris MM (2011) Streptomyces hyderabadensis sp. nov. an actinomycete isolated from soil. Int J Syst Evol Microbiol 61:76-80

Rong X, Huang Y (2010) Taxonomic evaluation of the Streptomyces griseus clade using mulitilocus sequence analysis and DNA-DNA hybridization, with proposal to combine 29 species and three subspecies as 11 genomic species. Int J Syst Evol Microbiol 60:696-703

Rong X, Huang Y (2012) Taxonomic evaluation of the Streptomyces hygroscopicus clade using multilocus sequence analysis and DNA-DNA hybridization, validating the MLSA scheme for the systematics of the whole genus. Syst Appl Microbiol 35:7-18

Rong X, Guo Y, Huang Y (2009) Proposal to reclassify the Streptomyces albidoflavus clade based on the basis of multilocus sequence analysis and DNA-DNA hybridization, and taxonomic elucidation of Streptomyces griseus subsp. solvifaciens. Syst Appl Microbiol 32:314-322

Saitou N, Nei M (1987) The neighbor-joining method: a new method for reconstructing phylogenetic trees. Mol Biol Evol 4:406-425 
Santhanam R, Okoro CK, Rong X, Huang Y, Bull AT, Woen Y, Andrews BA, Asenjo JA, Goodfellow M (2012a) Streptomyces atacamensis sp. nov., isolated from an extreme hyper-arid soil of the Atacama Desert. Int J Syst Evol Microbiol 62:2680-2684

Santhanam R, Okoro CK, Rong X, Huang Y, Bull AT, Andrews BA, Asenjo AJ, Weon HY, Goodfellow M (2012b) Streptomyces deserti sp. nov., isolated from hyper-arid desert soil. Antonie Van Leeuwenhoek 101:575-581

Santhanam R, Rong X, Huang Y, Andrews BA, Asenjo JA, Goodfellow M (2013) Streptomyces bullii sp nov., isolated from a hyper-arid Atacama Desert soil. Antonie Van Leeuwenhoek 103:367-373

Sasser M (1990) Identification of bacteria by gas chromatography of cellular fatty acids, MIDI Technical Note 101. MIDI Inc., Newark

Schulze D, Beese P, Ohlendorf B, Erhard A, Zinecker H, Dorador C, Imhoff J (2011) Abenquines A-D: aminoquinone derivatives produced by Streptomyces sp. strain DB634. J Antibiot Tokyo 64:763-768

Sentausa E, Fournier PE (2013) Advantages and limitations of genomics in prokaryotic taxonomy. Clin Microbiol Infect 19:790-795

Shirling EB, Gottlieb D (1966) Methods for characterization of Streptomyces species. Int J Syst Evol Microbiol 16:313-340

Sutcliffe IC, Trujillo ME, Goodfellow M (2012) A call to arms for systematists: revitalizing the purpose and practices underpinning the description of novel microbial taxa. Antonie Van Leeuwenhoek 101:13-20

Tamura K, Nei M (1993) Estimation of the number of nucleotide substitutions in the control region of mitochondrial DNA in humans and chimpanzees. Mol Biol Evol 10:512-526

Tamura K, Peterson D, Peterson N, Stecher G, Nei M, Kumar S (2011) MEGA5: molecular evolutionary genetics analysis using maximum likelihood, evolutionary distance, and maximum parsimony methods. Mol Biol Evol 28:2731-2739

Thompson JD, Higgins DG, Gibson TJ (1994) CLUSTAL W: improving the sensitivity of progressive multiple sequence alignment through sequence weighting position-specific gap penalties and weight matrix choice. Nucleic Acids Res 22:4673-4680

Traag BA, van Wezel GP (2008) The SsgA-like proteins in actinomycetes: small proteins up to a big task. Antonie Van Leeuwenhoek 94:85-97

Wayne LG, Brenner DJ, Colwell RR, Grimont PAB, Kandler O, Krichevsky MI, Moore LH, Moore WEC, Murray RGE, Stackebrandt E, Starr MP, Trüper HG (1987) International Committee on systematic bacteriology report on the ad hoc committee on reconciliation of approaches to bacterial systematics. Int J Syst Bacteriol 37:463-464

Whitman WB (2011) Intent of the nomenclatural code and recommendations about naming species based on genomic sequences. The Bulletin of BIMIS 2:135-139

Willemse J, Borst JW, de Waal E, Bisseling T, van Wezel GP (2011) Positive control of cell division: FtsZ is recruited by SsgB during sporulation of Streptomyces. Genes Dev 25:89-99

Williams PG (2008) Panning for chemical gold: marine bacteria as a source of new therapeutics. Trends Biotechnol 27:45-52

Williams ST, Goodfellow M, Alderson G, Wellington EMH, Sneath PHA, Sackin MJ (1983) Numerical classification of Streptomyces and related genera. J Gen Microbiol 129:1743-1813

Zerbino DR, Birney E (2008) Velvet: algorithms for de novo short read assembly using Bruijn graphs. Genome Res 18:821-829 